\title{
Leak detection method for bottom plate of oil tank based on oil/gas leak detection
}

Fei Wang*, Aishe Shui, Libei Zeng

Department of Military Logistics Engineering, Army Logistical University of PLA Chongqing, China

Corresponding Author Email: 435059333@qq.com

https://doi.org/10.18280/ijht.360328

Received: 19 November 2017

Accepted: 26 May 2018

\section{Keywords:}

oil/gas leak detection, fuzzy evaluation, oil/gas collection

\begin{abstract}
This paper aims to develop a desirable detection method for bottom plate leakage, especially initial leakage, of oil tanks. For this purpose, a leak detection method was presented based on the oil and gas analysis. Meanwhile, the drilling, sealing and oil/gas collection methods were presented to overcome the lack of oil/gas collection hole at the bottom of in-service oil tanks. For better evaluation of detection results, the author developed a normalization method for the results detected at multiple holes and created comprehensive evaluation criteria for these results. The established model and evaluation algorithm were validated by applying them to an actual case and analysing the detection results.
\end{abstract}

\section{INTRODUCTION}

For oil tanks, there is a gap between the exposed part of the bottom and the foundation. This gap should be filled up with a sealing paste to prevent water from entering the bottom through the gap and cause electrochemical corrosion to the bottom plate. In this way, a relatively closed underground space is formed inside the foundation, leading to long-term erosion of the bottom plate by the environmental media. What is worse, the closed structure makes it difficult to detect the leakage of the bottom plate quickly from the outside.

Fortunately, the bottom plate leak detection of oil tanks is made possible by the development of portable intrinsically safe PID volatile organic gas detector. Unlike traditional high-sensitive precision gas analysis instruments, this detector is easy to carry, convenient for field application and sensitive at the PPB or PPM level. On the downside, however, protable precision gas analysis instruments have limited adaptability to harsh environments, cost lots of money to buy or maintain, and does not support continuous leak detection [1-4]. Considering these advantages and disadvantages, these instruments should be combined with the continuous detection method, and, depending on the situation, applied to the manual inspection of oil tanks which have been in service for a long time and may suffer from oil and gas leakage, thereby reducing the cost of emptying and washing too many oil tanks [1-4].

In view of the difficulties in leak detection of oil tank bottom plate, this paper puts forward a leak detection method based on the oil and gas analysis. Meanwhile, the drilling, sealing and oil/gas collection methods were presented to overcome the lack of oil/gas collection hole at the bottom of in-service oil tanks. For better evaluation of detection results, the author established a fuzzy comprehensive evaluation model of the detection results, which compares the results of multiple detection holes at the same time (horizontal comparison) and the results of the same hole at different times (vertical comparison). The established model and evaluation algorithm were validated by applying them to an actual case and analysing the detection results

\section{DIFFUSION MECHANISM OF OIL/GAS LEAKED FROM THE FOUNDATION OF OIL TANKS}

\subsection{Basic features of oil tanks}

Figure 1 illustrates the main structural parts of oil tank foundation. From top to bottom, the foundation consists of a tar sand cushion, a sand cushion, a packing layer and a base layer. [5-7] On the periphery, the foundation is surrounded by a concrete ring beam or protective slope [5-7]. As shown in Figuree 1, the tar sand cushion is in direct contact with the bottom plate; the sand cushion below the tar sand cushion mainly drains the capillary groundwater and ensures the uniform pressure and load on the foundation. In the case of bottom plate leakage, the oil or gas will firstly diffuse in the foundation. For most in-service oil tanks, it is difficult to detect bottom plate leakage, owing to the lake of oil/gas collection hole on the foundation.

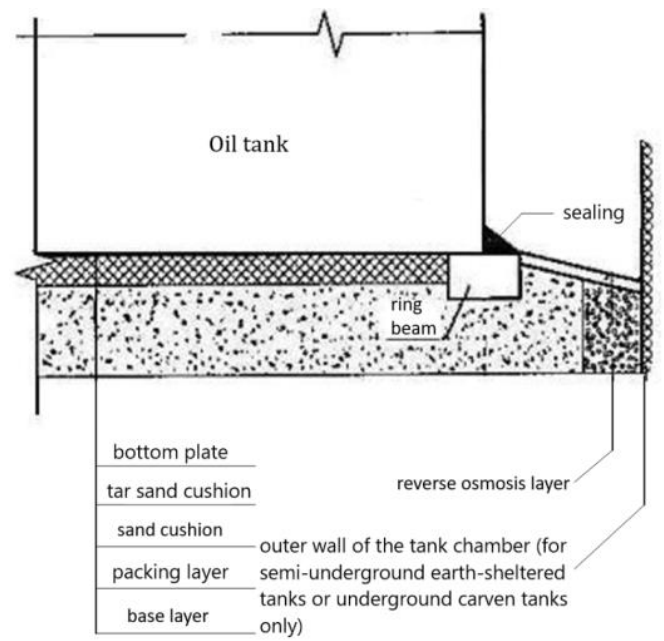

Figure 1. Structure of oil tank foundation 


\subsection{Oil/gas diffusion model for porous media}

Using the continuum medium method for porous media, the sand of the tank foundation can be simplified as a continuous porous medium, which falls in the range of continuum mechanics theory for fluids. Here, the diffusion process of leaked oil/gas is simplified under the following assumptions:

(1) The initial oil/gas concentration in the tank foundation is $0 \mathrm{ppm}$ before the leakage;

(2) The oil medium is completely volatilized after the leakage; the oil/gas diffuses as a slow, laminar flow;

(3) The outer boundary wall of the tank foundation is rigid and impermeable, and there is no fluid-solid coupling between the wall and the gas flow;

(4) In the circular confined space, the leaked oil/gas diffuses at normal temperature and pressure, and no chemical reaction occurs between the oil/gas and the air;

(5) The temperature in the foundation is the same as the ambient temperature, eliminating the possibility of heat exchange.

A part of LNAPL leaks into saturated water of tank foundation sand cushion due to dissolution, and a part of LNAPL leaks into pore gas due to volatilization, thus forming multiphase seepage of free LNAPL phase, water phase and gas phase in tank foundation sand cushion. Based on the hypothesis and simplification, it can be considered that the process of oil and gas leakage and diffusion in the confined space of tank foundation is a single-phase multicomponent diffusion problem without chemical reaction. Fluid flow and diffusion are governed by the laws of physical conservation. The basic conservation laws include the laws of mass, momentum and energy conservation. The governing equation is the mathematical description of these conservation laws. Assuming that the law of phase migration follows Darcy's law, the distribution of LNAPL concentration field in unsaturated zone is mainly described by two control equations: one is the concentration equation of LNAPL in saturated water, the other is the concentration equation of LNAPL in pore gas.

According to Reference [8], the light non-aqueous phase liquid (LNAPL) concentration in pore gas can be expressed as:

$$
\phi S \frac{\partial C}{\partial t}=\frac{\partial}{\partial x_{i}}\left[\phi S \mathbf{D}_{\mathrm{ij}} \frac{\partial C}{\partial x_{j}}\right]-\mathbf{q}_{\mathbf{i}} \frac{\partial C}{\partial x_{i}}-\lambda C+M
$$

where, $\emptyset$ is the effective porosity of the sand medium; $S$ is the gas phase saturation; $C$ is the LNAPL concentration in the gas phase $\left[\mathrm{kg} \cdot \mathrm{m}^{-3}\right] ; \mathrm{D}_{\mathrm{ij}}$ is the component of the diffusion coefficient tensor of the gas phase in the $\mathrm{i}-\mathrm{j}$ plane; $x_{i}$ are the spatial position coordinates in the $\mathrm{i}$-th direction $[\mathrm{m}] ; \mathrm{q}_{\mathrm{i}}$ is the average gas flow rate $[\mathrm{m} / \mathrm{s}] ; \lambda$ is the degradation rate coefficient of LNAPL component in the gas phase [1/s]; $M$ is the source sink generated from interphase dissolution, volatilization and adsorption $\left[\mathrm{kg} \cdot \mathrm{m}^{-3} / \mathrm{s}\right]$.

\subsection{Numerical simulation of leaked oil/gas diffusion process in tank foundation}

To disclose the diffusion trend and temporal and spatial concentration distribution of the oil/gas leaked from the confined space in tank foundation, a physical model of leaked oil-gas diffusion was established to numerically simulate the diffusion of leaked oil/gas, and the simulation results were compared with those of the simulation experiment under the same working conditions [9 11].

\subsubsection{Establishment of physical model}

The simulation object and its parameters are as follows: the $3.81 \mathrm{~m}$ radius oil tank stores diesel whose density is 840 $\mathrm{kg} \cdot \mathrm{m}-3$; the tank foundation is a homogeneous sand cushion; the oil concentration is 0 before the simulation; the centre point $(0,0)$ of the bottom plate has a corrosion perforation (diameter: $10 \mathrm{~mm}$ ), through which the oil leaks from the tank directly into the sand cushion. The numerical simulation results of the diffusion at points $1 \# \sim 4 \#$ were extracted to create the physical model below (Figure 3).

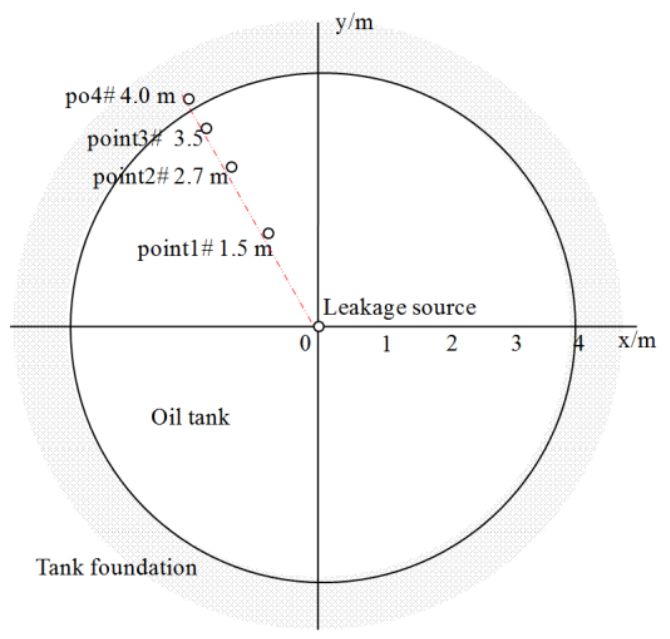

Figure 2. Physical model for numerical simulation

\subsubsection{Numerical simulation method}

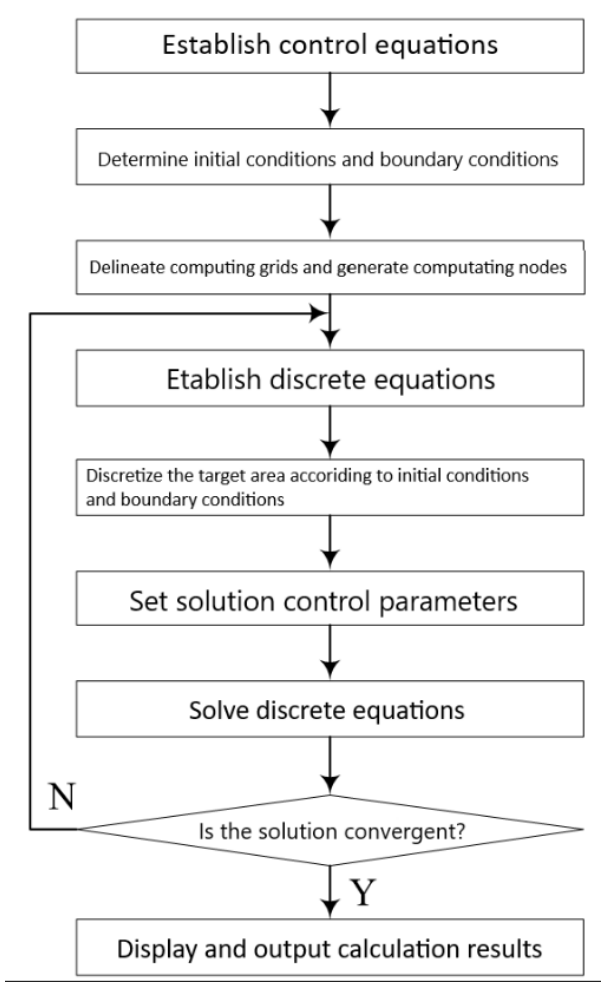

Figure 3. Workflow of numerical simulation 
For the $10 \mathrm{~mm}$-radius circle centring on the centre of the corrosion perforation $(0,0)$, the leaked oil/gas concentration was set to $1,000 \mathrm{ppm}$, and the speed of the continuous diesel inflow from the bottom plate was set to $1.8 \mathrm{~mL} / \mathrm{min}$. The outer boundary of the tank foundation was simulated as a $3.81 \mathrm{~m}$-radius circle centring on $(0,0)$. Generally, the medium sand with a maximum particle size of less than $20 \mathrm{~mm}$ is used for the sand cushion of the tank foundation, and its water saturation is about 0.2. The relevant empirical parameters of numerical simulation are as follows:

The effective porosity of sand media $\varnothing$ is 0.4 , the air density is $0.0129\left[\mathrm{~kg} \cdot \mathrm{m}^{-3}\right]$, the intrinsic permeability coefficient $S$ is $1 \times 10^{-6}$, the radial diffusion coefficient $D_{i j}$ is $2 \times 10^{-4}$, the average flow rate of diesel oil $\mathrm{q}_{\mathrm{i}}$ is $0.0125 \mathrm{~m} / \mathrm{s}$, the degradation rate coefficient of diesel oil in gas phase $\lambda$ is $0 \mathrm{l} / \mathrm{s}$, and the source and $\operatorname{sink} M$ is $0 \mathrm{~kg} \cdot \mathrm{m}^{-3} / \mathrm{s}$.

The oil/gas diffusion of the tank foundation was simulated numerically on the largescale CFD software FLUENT. The workflow is shown in Figure 3.

\subsubsection{Simulation results and analysis}

The simulation time and step length were set to $(0: 10: 30)$. The simulation results on the variation of leaked oil/gas concentration with time are shown in Figure 4 below

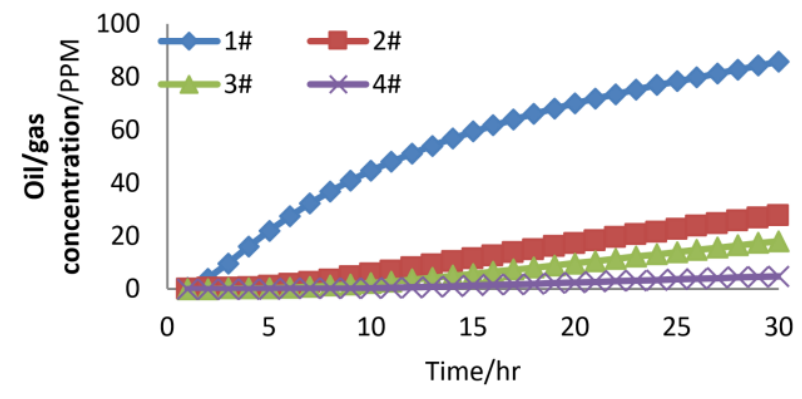

Figure 4. Simualtion results on the leaked oil/gas

It can be seen from the above figure that the diesel leaked from the perforation $(0,0)$ of the bottom plate continuously at $1.8 \mathrm{~mL} / \mathrm{min}$. The oil/gas concentration decreased with the increase of the distance from the leak source, forming a gradient change in terms of concentration distribution. After $27 \mathrm{hr}$ of leakage, the oil/gas diffused to the edge of the tank foundation. The oil/gas concentration was greater than $3 \mathrm{ppm}$ for all holes $1 \# \sim 4 \#$. The results indicate that the proposed oil/gas detection method can identify micro-leakage of the bottom plate at the edge of the foundation in a timely manner.

\section{OIL/GAS COLLECTION METHOD}

\subsection{Leak detector selection}

Considering the accuracy and sensitivity of oil and gas [12] detection, the PhoCheck+2000Ex portable PID detector of British Ion Company is selected. Its maximum measurement range is $0.1 \mathrm{ppm} 4000 \mathrm{ppm}$, response and recovery time is $90 \mathrm{~ms} \sim 1 \mathrm{~s}$, working temperature is $-20 \sim 60^{\circ} \mathrm{C}$, working humidity is $0 \sim 99 \%$.

\subsection{Drilling detection holes}

(1) With the tank centre as the origin, the coordinates were determined for each detection hole of the tank. Taking the $3.81 \mathrm{~m}$-radius tank for example, the coordinates of the four holes are respectively $1 \#(3.96,0), 2 \#(0,3.96), 3 \#(-3.96,0)$ and $4 \#(0,-3.96)$ (Figure 5).

(2) Four $12 \mathrm{~mm}$-diameter and $250 \mathrm{~mm}$-depth detection holes were drilled according to the said coordinates. The holes are deep enough to reach the sand cushion. The drilling angle ranges between $60^{\circ}$ and $90^{\circ}$. Once the holes were completed, they were sealed up with $2 \#$ silicone plugs coated with vaseline (Figure 6). Before drilling, the tank chamber was subjected to oil/gas safety inspection. The holes were drilled using explosion-proof copper hammer and the drill bit. For saefty, a rubber pad was inserted between the hammer and the bit. In the course of drilling, the drill bit end was applied with butter or washed with water, aiming to prevent overheating.

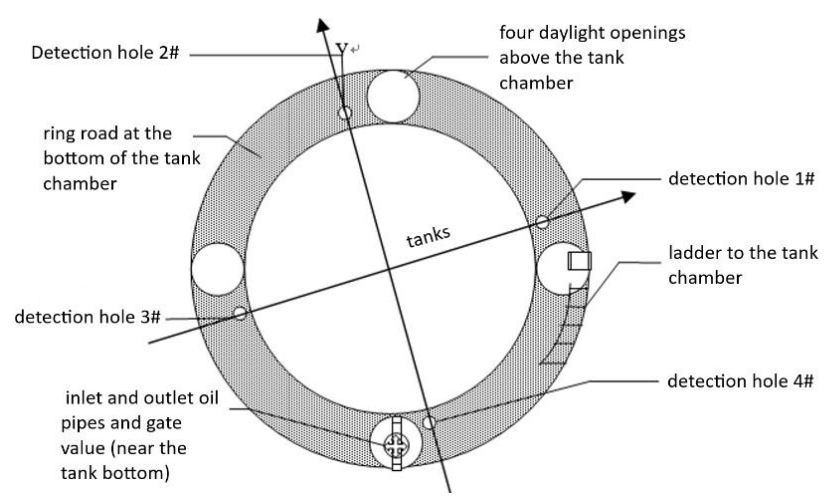

Figure 5. Positions of the four detection holes

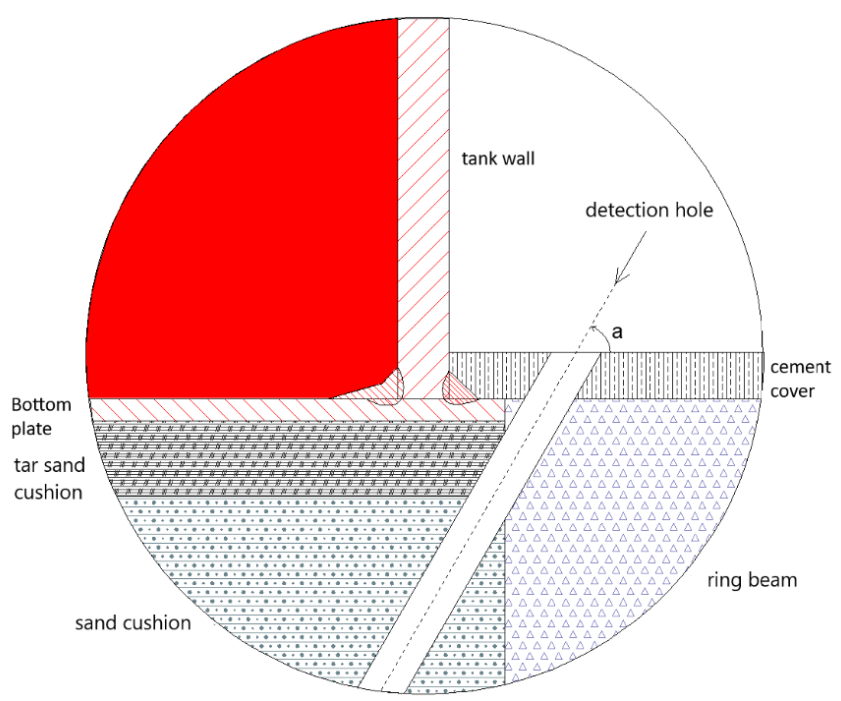

Figure 6. Drilling method

\subsection{Oil/gas collection}

(1) One hour after the completion of drilling, the initial measured values of the tank were obtained from each detection hole for reference. As shown in Figure 7 blow, the probe of the oil/gas detector was used to pierce the upper end of the silicone plug, and the gas sample was extracted from the detection hole by the air pump of the PID instrument. The oil/gas concentration was measured at the same time. The silicone plug is so elastic that it could seal up the detection 
hole once the probe is removed.

(2) Then, each detection hole was checked at the frequency of routine or special sampling (once per day or once per hour). Meanwhile, the oil/gas concentration of the tank chamber was measured and recorded.

(3) The oil/gas concentration collected by the portable PID detector was transmitted wirelessly via infrared for data collection and pre-processing. The contour map of oil/gas concentration field was plotted to visually display the distribution of the oil-gas concentration field of tank foundation (Figure 8).

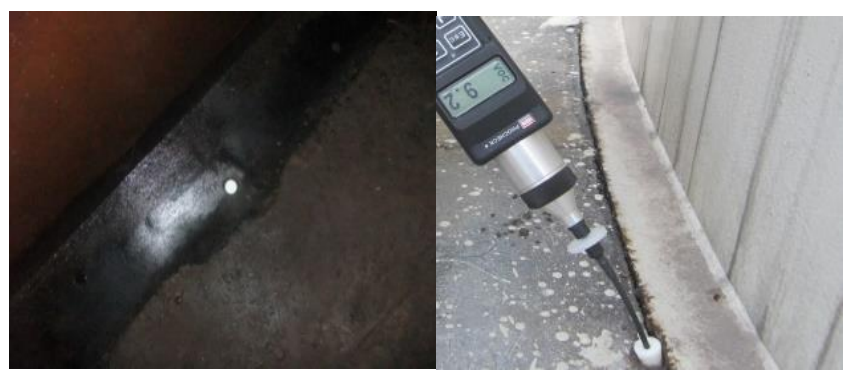

Figure 7. On-site oil/gas detection

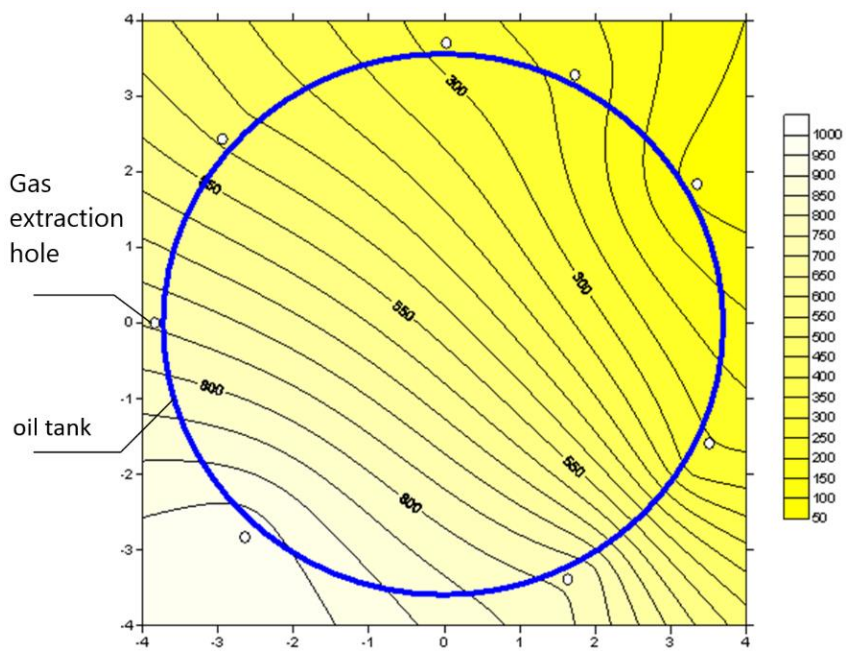

Figure 8. Contour map of oil/gas concentration field of tank foundation

\section{FUZZY COMPREHENSIVE EVALUATION METHOD FOR LEAK DETECTION RESULTS}

Based on the fuzzy technology, a fuzzy comprehensive evaluation method was proposed for leak detection results. The relevant decision model and algorithm were also presented, laying the basis for programmatic automatic evaluation.

\subsection{Fuzzy normalization of oil/gas concentrations}

The fuzzy correction coefficient $\mu$ was introduced to control the the oil/gas pollution surrounding tank foundation. Using the fuzzy classification method, the oil/gas concentrations at the detection points of tank foundation were divided into 5 levels. Let $c_{i j}$ be the oil/gas concentration measured at the $\mathrm{j}$-th time at the $\mathrm{i}$-th sampling point. Then, the fuzzy value $S_{i j}$ of $c_{i j}$ can be expressed as:

$$
S_{i j}= \begin{cases}0 & c_{i j}<3 \mu \mathrm{ppm} \\ 1 & 3 \mu \mathrm{ppm} \leq c_{i j}<15 \mu \mathrm{ppm} \\ 2 & 15 \mu \mathrm{ppm} \leq c_{i j}<100 \mu \mathrm{ppm} \\ 3 & 100 \mu \mathrm{ppm} \leq c_{i j}<1000 \mu \mathrm{ppm} \\ 4 & c_{i j} \geq 1000 \mu \mathrm{ppm}\end{cases}
$$

The value of $\mu$ depends on the oil type, tank type, construction age of the tank, and the ambient temperature and humidity. Hence, a tank which has not leaked after regular maintenance was selected for reference. Let $c_{r}$ be the oil/gas concentration of the $r$-th sampling hole of the reference tank $(r=1 \sim n)$. Then, the value of $\mu$ can be determined by:

$$
\mu=\frac{1}{3 n} \sum_{r=1}^{n} c_{r}
$$

The value of $\mu$ should be 1 if $\mu<1$ or no reference tank is available.

\subsection{Horizontal fuzzy evaluation}

According to the fuzzy classification of oil/gas concentration data, the leakage at the bottom plate of the oil tank was evaluated by the portable leak detector through the comparison of the detection results acquired at the same time from different holes:

$$
\begin{aligned}
& S_{L}(j)= \begin{cases}0 & S_{M A X j}=0 \\
1 & S_{M A X j}=1 \\
2 & S_{M A X j}=2 \text { AND } 1<S_{A V E j} \leq 2 \\
3 & S_{M A X j}=4 \text { OR } 2<S_{A V E j} \leq 3\end{cases} \\
& S_{M A X j}=\operatorname{MAX}\left(S_{1 j}, S_{2 j}, \cdots, S_{n j}\right) \\
& S_{M I N j}=\operatorname{MIN}\left(S_{1 j}, S_{2 j}, \cdots, S_{n j}\right) \\
& S_{A V E j}=\operatorname{AVERAGE}\left(S_{1 j}, S_{2 j}, \cdots, S_{n j}\right)
\end{aligned}
$$

where $S_{L}(j)$ is the leak state acquired in the j-th detection ( 0 : no leak; 1 and 2: possible leak; 3: leak); $S_{M A X j}, S_{M I N j}$ and $S_{A V E j}$ are the maximum, minimum and mean of the fuzzy values of $\mathrm{n}$ detection holes, respectively; $\mathrm{n}$ is the total number of detection holes; $\mathrm{j}$ is the number of detections $(\mathrm{j} \geq 1)$.

\subsection{Vertical fuzzy comprehensive evaluation}

If $1 \leq \mathrm{S}_{\mathrm{L}}(\mathrm{j}) \leq 2$, there is a possibility of leakage. In this case, it is necessary to conduct further evaluation using the vertical fuzzy evaluation results at different times. At least two more samplings should be performed at the special sampling frequency, to ensure that $j \geq 3$.

The vertical variation $\Delta S_{L}(j)$, the sum $\Delta S_{L S U M}$ and the maximum value $S_{L S U M}$ of $S_{L}(j)$ can be expressed as: 


$$
\begin{aligned}
& \Delta S_{L}(j)=S_{L}(j)-S_{L}(j-1) \\
& \Delta S_{L S U M}=\operatorname{SUM}\left(\Delta S_{L}(j), \Delta S_{L}(j-1), \cdots \Delta S_{L}(2)\right) \\
& S_{L M A X}=\operatorname{MAX}\left(S_{L}(j), S_{L}(j-1), \cdots, S_{L}(1)\right)
\end{aligned}
$$

Thus, the result of the vertical fuzzy comprehensive evaluation can be expressed as:

$$
S_{L}= \begin{cases}1 & \left(\Delta S_{L S U M}<0 \text { AND } S_{L M A X}=2\right) \text { OR }\left(\Delta S_{L S U M} \leq j / 2 \text { AND } S_{L M A X}=1\right) \\ 2 & 0 \leq \Delta S_{L S U M} \leq j / 2 \text { AND } S_{L M A X}=2 \\ 3 & \Delta S_{L S U M}>j / 2\end{cases}
$$

where 1 means there is a leak before the repair; 2 means a leak source exists outside the foundation; 3 means a leak has occurred.

\section{APPLICATION TEST AND RESULTS ANALYSIS}

To verify the validity and reliability of the portable leak detection system and fuzzy evaluation criteria, the portable leak detection system was applied to detect the tank leakage in tank farms A and B. In total, 41 oil tanks were under detection, all of which had been in service for more than 30 years.

Since the tank farms had never been subjected to oil/gas leak detection before, no historical oil/gas detection data were available for reference. Hence, a tank which had not leaked after regular maintenance was selected for reference. According to equation (3), the fuzzy correction coefficient $\mu$ was set to 1 . In light of the data acquired by our system from the 41 tanks, the evaluation results by the criteria of horizontal fuzzy comprehensive evaluation are as follows: 31 tanks had no leak, 2 tanks had leaked and 8 may had leaked.

\subsection{Leak-free tanks}

In 31 tanks, the oil/gas concentration satisfies:

$c_{i 1}<3 \mu=3 \mathrm{ppm}$

where $i=[1,2,3,4]$ because there are 4 sampling holes.

From equations (12) and (2), the fuzzy oil/gas concentration acquired by the 1 st detection from the 31 tanks was determined as $S_{i 1}=0$; From equation (5), the maximum fuzzy value was calculated as $S_{M A X 1}=0$; From equation (4), the leak state was identified as $S_{L}(1)=0$. Thus, it is concluded that the 31 tanks were free from leakage.

\subsection{Leaked tanks}

\begin{tabular}{|c|c|c|c|c|c|c|c|c|c|}
\hline \multirow{2}{*}{$\begin{array}{c}\text { No. } \\
1\end{array}$} & \multirow{2}{*}{$\begin{array}{c}\text { Time/hr } \\
0\end{array}$} & \multicolumn{2}{|c|}{$\begin{array}{c}\text { Concentration at hole } \\
\# 1 \\
\text { ppm Fuzzy }\end{array}$} & \multicolumn{2}{|c|}{$\begin{array}{c}\text { Concentration at hole } \\
\# 2 \\
\text { ppm Fuzzy }\end{array}$} & \multicolumn{2}{|c|}{$\begin{array}{c}\text { Concentration at hole } \\
\# 3 \\
\text { ppm Fuzzy }\end{array}$} & \multicolumn{2}{|c|}{$\begin{array}{c}\text { Concentration at hole } \\
\# 4 \\
\text { ppm Fuzzy } \\
\end{array}$} \\
\hline & & 1 & 0 & 30.7 & 2 & 19.4 & 2 & 1600 & 4 \\
\hline 2 & 24 & 3.7 & 1 & 35.6 & 2 & 24.8 & 2 & 1690 & 4 \\
\hline 3 & 48 & 2.7 & 0 & 22.5 & 2 & 15.2 & 2 & 1630 & 4 \\
\hline
\end{tabular}

The leaked tanks were $4 \#$ in tank farm $\mathrm{A}$ and $11 \#$ in tank farm B. The oil/gas concentration data at the foundation are

\begin{tabular}{|c|c|c|c|c|c|c|c|c|c|}
\hline No. & Time/hr & $\begin{array}{c}\text { Concentrati } \\
\text { ppm }\end{array}$ & $\begin{array}{l}\text { on at hole \#1 } \\
\text { Fuzzy }\end{array}$ & $\begin{array}{c}\text { Concentrat } \\
\mathrm{ppm}\end{array}$ & $\begin{array}{l}\text { on at hole \#2 } \\
\text { Fuzzy }\end{array}$ & $\begin{array}{c}\text { Concentrat } \\
\text { ppm }\end{array}$ & $\begin{array}{l}\text { on at hole \#3 } \\
\text { Fuzzy }\end{array}$ & $\begin{array}{c}\text { Concentrat } \\
\text { ppm }\end{array}$ & $\begin{array}{l}\text { on at hole \#4 } \\
\text { Fuzzy }\end{array}$ \\
\hline 1 & 0 & 1140 & 4 & 1060 & 4 & 1720 & 1 & 783 & 3 \\
\hline 2 & 24 & 1380 & 4 & 1150 & 4 & 2280 & 1 & 756 & 3 \\
\hline 3 & 48 & 1040 & 4 & 1005 & 4 & 1350 & 1 & 700 & 3 \\
\hline
\end{tabular}
listed in Tables 1 and 2. For each leaked tank, three tests were carried out. Note that $j=[1,2,3]$.

Table 1. Oil/gas concentration at the foundation of tank 4\# in tank farm A

Table 2. Oil/gas concentration at the foundation of tank 11\# in tank farm B

In the three leak tests, the leak states of the two tanks were $S_{L}(1)=S_{L}(2)=S_{L}(3)=3$, indicating that both tanks suffered from leakage.

On-site inspection found a possible leak source on the bottom plate of tank $4 \#$ near detection point $4 \#$. This leak source is attributable to the corrosion perforation or weld cracking of the bottom plate at this point. Besides, the external observation revealed that asphalt was dissolved and overflowed near this position. Then, the tanks were opened to verify the conclusion of oil/gas leak tests.

According to the inspection record of tank $11 \#$ in tank farm $\mathrm{B}$, this tank was emptied due to the abnormal decrease of the stored oil, which was detected by manual gauge measurement. However, the result of manual guage measurement often has some delay, i.e. lots of oil had been leaked to the foundation by the time the leak was discovered. Hence, the oil/gas concentration in the tank foundation was stabilized at a high level for a long time (c>1,000ppm).

\subsection{Possibly leaked tanks}

Tanks 1\#, 2\# and 3\# of tank farm A and tanks 7\#, 12\#, 13\# and 14\# of tank farm B, all of which are earth-sheltered and contain gasoline, may had leaked. The results of oil/gas concentrations in the foundation of these tanks are shown in Tables 3 10. 
Table 3. Foundation oil/gas concentration of tank 1\# in tank farm A

\begin{tabular}{|c|c|c|c|c|c|c|c|c|c|}
\hline \multirow{2}{*}{$\frac{\text { No. }}{1}$} & \multirow{2}{*}{$\frac{\text { Time/hr }}{0}$} & \multicolumn{2}{|c|}{$\begin{array}{l}\text { Concentration at hole \#1 } \\
\text { ppm Fuzzy }\end{array}$} & \multicolumn{2}{|c|}{$\begin{array}{l}\text { Concentration at hole \#2 } \\
\text { ppm Fuzzy }\end{array}$} & \multicolumn{2}{|c|}{$\begin{array}{l}\text { Concentration at hole \#3 } \\
\text { ppm Fuzzy }\end{array}$} & \multicolumn{2}{|c|}{$\begin{array}{l}\text { Concentration at hole \#4 } \\
\text { ppm Fuzzy }\end{array}$} \\
\hline & & 0.5 & 1 & 1.7 & 1 & 4.2 & 0 & 4.3 & 1 \\
\hline 2 & 24 & 0.4 & 1 & 2.3 & 1 & 4.6 & 0 & 5.7 & 1 \\
\hline 3 & 48 & 1.9 & 1 & 6.3 & 1 & 4.4 & 0 & 6.4 & 1 \\
\hline
\end{tabular}

Table 4. Foundation oil/gas concentration of tank $2 \#$ in tank farm A

\begin{tabular}{|c|c|c|c|c|c|c|c|c|c|}
\hline \multirow{2}{*}{ No. } & \multirow{2}{*}{$\begin{array}{c}\text { Time } / \mathrm{hr} \\
0\end{array}$} & \multicolumn{2}{|c|}{$\begin{array}{l}\text { Concentration at hole \#1 } \\
\text { ppm Fuzzy }\end{array}$} & \multicolumn{2}{|c|}{$\begin{array}{l}\text { Concentration at hole \#2 } \\
\text { ppm Fuzzy }\end{array}$} & \multicolumn{2}{|c|}{$\begin{array}{l}\text { Concentration at hole \#3 } \\
\text { ppm Fuzzy }\end{array}$} & \multicolumn{2}{|c|}{$\begin{array}{l}\text { Concentration at hole \#4 } \\
\text { ppm Fuzzy }\end{array}$} \\
\hline & & 10.8 & 1 & 7.0 & 1 & 6.3 & 1 & 7.9 & 1 \\
\hline 2 & 24 & 6.7 & 1 & 6.2 & 1 & 8.8 & 1 & 5.7 & 1 \\
\hline 3 & 48 & 9.6 & 1 & 8.8 & 1 & 5.8 & 1 & 7.6 & 1 \\
\hline
\end{tabular}

Table 5. Foundation oil/gas concentration of tank $3 \#$ in tank farm A

\begin{tabular}{|c|c|c|c|c|c|c|c|c|c|}
\hline No. & Time/hr & $\begin{array}{l}\text { Concentratio } \\
\text { ppm Fuzzy }\end{array}$ & ole \#1 & $\begin{array}{l}\text { Concentrat } \\
\text { ppm Fuzzy }\end{array}$ & le \#2 & $\begin{array}{l}\text { Concentrat } \\
\text { ppm Fuzzy }\end{array}$ & le \#3 & \multicolumn{2}{|c|}{$\begin{array}{l}\text { Concentration at hole \#4 } \\
\text { ppm Fuzzy }\end{array}$} \\
\hline 1 & 0 & 8.8 & 1 & 6.0 & 1 & 10.0 & 0 & 4.9 & 1 \\
\hline 2 & 24 & 7.1 & 1 & 7.2 & 1 & 11.2 & 0 & 6.4 & 1 \\
\hline 3 & 48 & 7.8 & 1 & 6.3 & 1 & 10.9 & 0 & 4.7 & 1 \\
\hline
\end{tabular}

Table 6. Foundation oil/gas concentration of tank 5\# in tank farm A

\begin{tabular}{ccccccccccc}
\hline \hline \multirow{2}{*}{ No. } & \multirow{2}{*}{ Time/hr } & \multicolumn{2}{l}{$\begin{array}{l}\text { Concentration at hole \#1 } \\
\text { ppm }\end{array}$} & Fuzzy & & \multicolumn{2}{l}{ Concentration at hole \#2 } & \multicolumn{2}{l}{ Concentration at hole \#3 } & \multicolumn{2}{l}{ Concentration at hole \#4 } \\
& & ppm & Fuzzy & & ppm & Fuzzy & ppm & Fuzzy \\
\hline 1 & 0 & 9.6 & 1 & 8.8 & 1 & 10.0 & 0 & 6.7 & 1 \\
2 & 24 & 7.3 & 1 & 7.6 & 1 & 8.2 & 0 & 8.5 & 1 \\
3 & 48 & 6.9 & 1 & 6.3 & 1 & 8.4 & 0 & 8.7 & 1 \\
\hline \hline
\end{tabular}

Table 7. Foundation oil/gas concentration of tank 7\# in tank farm B

\begin{tabular}{|c|c|c|c|c|c|c|c|c|c|}
\hline \multirow{2}{*}{ No. } & \multirow{2}{*}{$\begin{array}{c}\text { Time/hr } \\
0\end{array}$} & \multicolumn{2}{|c|}{$\begin{array}{l}\text { Concentration at hole \#1 } \\
\text { ppm Fuzzy }\end{array}$} & \multicolumn{2}{|c|}{$\begin{array}{l}\text { Concentration at hole } \# 2 \\
\text { ppm Fuzzy }\end{array}$} & \multicolumn{2}{|c|}{$\begin{array}{l}\text { Concentration at hole \#3 } \\
\text { ppm Fuzzy }\end{array}$} & \multicolumn{2}{|c|}{$\begin{array}{l}\text { Concentration at hole \#4 } \\
\text { ppm Fuzzy }\end{array}$} \\
\hline & & 4.1 & 1 & 62.6 & 2 & 7.4 & 1 & 16.8 & 2 \\
\hline 2 & 24 & 4.6 & 1 & 79.1 & 2 & 7.6 & 1 & 10.2 & 1 \\
\hline 3 & 48 & 3.3 & 1 & 50.6 & 2 & 3.6 & 1 & 8.7 & 1 \\
\hline
\end{tabular}

Table 8. Foundation oil/gas concentration of tank 12\# in tank farm B

\begin{tabular}{|c|c|c|c|c|c|c|c|c|c|}
\hline No. & Time/hr & $\begin{array}{l}\text { Concentra } \\
\text { ppm Fuzzy }\end{array}$ & ole \#1 & $\begin{array}{l}\text { Concentra } \\
\text { ppm Fuzz }\end{array}$ & ole \#2 & $\begin{array}{l}\text { Concentrat } \\
\text { ppm Fuzzy }\end{array}$ & le \#3 & \multicolumn{2}{|c|}{$\begin{array}{l}\text { Concentration at hole \#4 } \\
\text { ppm Fuzzy }\end{array}$} \\
\hline 1 & 0 & 5.2 & 1 & 6.4 & 1 & 9.6 & 1 & 6.3 & 1 \\
\hline 2 & 24 & 3.8 & 1 & 5.7 & 1 & 10.2 & 1 & 4.3 & 1 \\
\hline 3 & 48 & 3.2 & 1 & 4.3 & 1 & 8.7 & 1 & 3.4 & 1 \\
\hline
\end{tabular}

It can be seen from Tables 3, 5, 6 and 10 that the normalized fuzzy value of oil/gas concentration of tanks 1\#, $3 \#$ and $5 \#$ in tank farm A and tank 14\# in tank farm B were the same. Therefore, these tanks were allocated to the first group.

As shown in Tables 4 and 8 , tank $2 \#$ in tank farm A and tank $12 \#$ in tank farm B shared the same normalized fuzzy value of oil/gas concentration. Thus, the two tanks were classified into the second group.

In addition, tank $7 \#$ in tank farm $B$ differed from all the other tanks in normalized fuzzy value of oil/gas concentration, and was thus put into the third group.

The parameter values for the fuzzy evaluation of the three groups were derived from equations (4) (10) and recorded in Table 11.
As can be seen from equation (4) and the $S_{L}(j)$ values in Table 11, the leak test results of groups 1,2 and 3 were possibly leaked. However, this conclusion requires further confirmation through vertical comprehensive evaluation.

Accoridng to the SL value in equation (11), the tanks in groups 1 and 2 suffered from leakage before the repair, which agrees with the historical maintenance record of the tank farms. Besides, the tank in group 3 had a leak source outside the foundation. It is observed that the hole 4\# lies close to the check valve of the inlet and outlet oil pipes. During the injection and extraction of oil, a small amount of oil leaked from the valve into the foundation below. Therefore, the high measured value can be attributed to the infiltration of the leaked oil from the valve to the foundation. 
Table 9. Foundation oil/gas concentration of tank 13\# in tank farm B

\begin{tabular}{|c|c|c|c|c|c|c|c|c|c|}
\hline \multirow{2}{*}{$\begin{array}{c}\text { No. } \\
1\end{array}$} & \multirow{2}{*}{$\begin{array}{c}\text { Time/hr } \\
0\end{array}$} & \multicolumn{2}{|c|}{$\begin{array}{l}\text { Concentration at hole \#1 } \\
\text { ppm Fuzzy }\end{array}$} & \multicolumn{2}{|c|}{$\begin{array}{l}\text { Concentration at hole \#2 } \\
\text { ppm Fuzzy }\end{array}$} & \multicolumn{2}{|c|}{$\begin{array}{l}\text { Concentration at hole \#3 } \\
\text { ppm Fuzzy }\end{array}$} & \multicolumn{2}{|c|}{$\begin{array}{l}\text { Concentration at hole \#4 } \\
\text { ppm Fuzzy }\end{array}$} \\
\hline & & 0 & 0 & 7.1 & 1 & 2.1 & 0 & 2.6 & 0 \\
\hline 2 & 24 & 2.4 & 0 & 5.0 & 1 & 1.0 & 0 & 1.3 & 0 \\
\hline 3 & 48 & 1.9 & 0 & 6.8 & 1 & 2.6 & 0 & 3.0 & 1 \\
\hline
\end{tabular}

Table 10. Foundation oil/gas concentration of tank 14\# in tank farm B

\begin{tabular}{|c|c|c|c|c|c|c|c|c|c|}
\hline No. & Time/hr & $\begin{array}{l}\text { Concentratio } \\
\text { ppm Fuzzy }\end{array}$ & ole \#1 & $\begin{array}{l}\text { Concentra } \\
\text { ppm Fuzzy }\end{array}$ & ple \#2 & $\begin{array}{l}\text { Concentr } \\
\text { ppm Fuzz }\end{array}$ & le \#3 & \multicolumn{2}{|c|}{$\begin{array}{l}\text { Concentration at hole \#4 } \\
\text { ppm Fuzzy }\end{array}$} \\
\hline 1 & 0 & 6.3 & 1 & 5.1 & 1 & 6.6 & 0 & 4.3 & 1 \\
\hline 2 & 24 & 5.5 & 1 & 4.4 & 1 & 6.4 & 0 & 7.7 & 1 \\
\hline 3 & 48 & 5.4 & 1 & 7.3 & 1 & 9.6 & 0 & 9.1 & 1 \\
\hline
\end{tabular}

Table 11. Parameter values for the fuzzy evaluation

\begin{tabular}{cccccccccc}
\hline \hline No. & $j$ & $S_{M A X j}$ & $S_{M I N j}$ & $S_{A V E j}$ & $S_{L}(j)$ & $S_{L}(j)$ & $S_{L S U M}$ & $S_{L M A X}$ & $S_{L}$ \\
\hline \multirow{3}{*}{1} & 1 & 1 & 0 & 0.67 & 1 & - & - & & \\
& 2 & 1 & 0 & 0.67 & 1 & 0 & 0 & 1 & 1 \\
& 3 & 1 & 0 & 0.67 & 1 & 0 & 0 & & \\
\hline \multirow{3}{*}{2} & 1 & 1 & 1 & 1 & 1 & - & - & & 1 \\
& 2 & 1 & 1 & 1 & 1 & 0 & 0 & 1 & \\
& 3 & 1 & 1 & 1 & 1 & 0 & 0 & & \\
\hline & 1 & 2 & 1 & 1.67 & 2 & - & - & & \\
& 2 & 2 & 1 & 1.33 & 2 & 0 & 0 & & \\
& 3 & 2 & 1 & 1.33 & 2 & 0 & 0 & & \\
\hline \hline
\end{tabular}

\section{CONCLUSIONS}

This paper analyses the diffusion mechanism and detection technique of leaked oil/gas in oil tank foundation, proposes a leak detection method for the bottom plate of oil tank based on oil/gas leak detection, and establishes fuzzy comprehensive evaluation criteria for the detection results. Meanwhile, the drilling, sealing and oil/gas collection methods were presented to overcome the lack of oil/gas collection hole at the bottom of in-service oil tanks. For better evaluation of detection results, the author established a fuzzy comprehensive evaluation model of the detection results, which compares the results of multiple detection holes at the same time (horizontal comparison) and the results of the same hole at different times (vertical comparison). The established model and evaluation algorithm were validated by applying them to an actual case and analysing the detection results. The results show that the proposed method does well in the detection of the state of actual oil tanks.

\section{ACKNOWLEDGMENT}

National Natural Science Foundation of China (61871402, $61271449,61302175)$, The first batch of hundred academic subjects in Chongqing (Yu Jiao people 2012-44), Natural Science Foundation of Chongqing (CSTC2015JCYJBX0017).

\section{REFERENCES}

[1] Lovelock JE. (1960). A photoionization detector for gases and vapours. Nature 188(4748): 401. http://dx.doi.org/10.1038/188401a0

[2] Davenport JN, Adlard ER. (1984). Photoionization detectors for gas chromatography. Journal of Chromatography A 290(MAY): 13-32. http://dx.doi.org/10.1016/S0021-9673(01)93557-5

[3] Freedman AN. (1980). The photoionization detector: Theory, performance and application as a low-level monitor of oil vapour. Journal of Chromatography A 190(2): 263-273.

[4] Sun J, Guan F, Cui D, Chen X, Zhang L, Chen J. (2013). An improved photoionization detector with a micro gas chromatography column for portable rapid gas chromatography system. Sensors and Actuators B: Chemical 188: 513-518. http://dx.doi.org/10.1016/j.snb.2013.07.066

[5] Liu XY. (2016). Study on corrosion trend prediction and reliability modeling of oil tanks. Harbin University of Technology.

[6] Gao J. (2016). Discussion on construction technology management of large scale oil tank foundation engineering. Engineering Quality (S1): 186-187+197.

[7] He LM, Gao Q. (2007). Construction of oil and gas storage and transportation engineering. Beijing: Petroleum Industry Press.

[8] Xue Q, Liang B, Feng X, Liu J. (2005). Multiphase flow numerical model of petroleum pollutant transport in underground environmental system. Journal of Chemical Engineering 56(5): 920-924.

[9] Grysakowski B. (2016). Numerical simulations of diffusion-migration processes in thin layers. Annales de Chimie: Science des Materiaux 40(1-2): 95-102.

[10] Sharma R, Mohamed M. (2003). An experimental 
investigation of LNAPL migration in an unsaturated/saturated sand. Engineering Geology 70(3): 305-313. http://dx.doi.org/10.1016/S00137952(03)00098-X

[11] Olaiju OA, Hoe YS, Ogunbode EB, Fabi JK, Egba EI. (2018). Achieving a sustainable environment using numerical method for the solution of advection equation in fluid dynamics. Chemical Engineering Transactions
63: 631-363. http://dx.doi.org/10.3303/CET1863106

[12] Sari EN, Prueksakorn K, Gonzalez JC, Arpornthip T, Areerob T, Pornsawang C, Pimonsree S. (2018). Inventory of greenhouse gas emissions for phayao province-an agricultural city in Thailand. Chemical Engineering Transactions 63: 163-168. http://dx.doi.org/10.3303/CET1863028 